\section{(6) OPEN ACCESS}

\title{
Effectiveness of a five-level Paediatric Triage System: an analysis of resource utilisation in the emergency department in Taiwan
}

\author{
Yu-Che Chang, ${ }^{1,2}$ Chip-Jin Ng, ${ }^{1}$ Chang-Teng Wu, ${ }^{3}$ Li-Chin Chen, ${ }^{4}$ Jih-Chang Chen, ${ }^{1}$ \\ Kuang-Hung $\mathrm{Hsu}^{5}$
}

- An additional appendix is published online only. To view this file please visit the journal online (http://dx.doi.org/10. 1136/emermed-2012-201362).

'Department of Emergency Medicine, Chang Gung Memorial Hospital Linkou and College of Medicine, Chang Gung University, Tao-Yuan, Taiwan

${ }^{2}$ Department of Medical Education, Chang Gung Memorial Hospital Linkou and College of Medicine, Chang Gung University, Tao-Yuan, Taiwan

${ }^{3}$ Division of Pediatric General Medicine, Department of Pediatrics, Chang Gung Memorial Hospital Linkou and College of Medicine, Chang Gung University, Tao-Yuan, Taiwan

${ }^{4}$ Department of Nursing, Chang Gung Memorial Hospital and Linkou and College of Medicine, Chang Gung University, Tao-Yuan, Taiwan ${ }^{5}$ Laboratory for Epidemiology, Department of Health Care Management, Chang Gung University, Tao-Yuan, Taiwan

\section{Correspondence to} Dr. Chip-Jin Ng or Professor Kuang-Hung Hsu,

Department of Health Care Management, Chang Gung University, No 259, Wen-Hwa 1st Rd., Kwei-Shan, Tao-Yuan 333; khsu@mail.cgu.edu.tw

Accepted 14 August 2012 Published Online First 14 September 2012

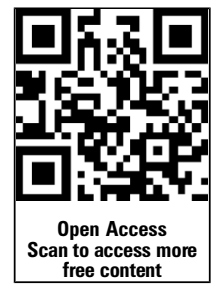

\section{ABSTRACT}

Objectives To examine the effectiveness of a five-level Paediatric Triage and Acuity System (Ped-TTAS) by comparing the reliability of patient prioritisation and resource utilisation with the four-level Paediatric Taiwan Triage System (Ped-TTS) among non-trauma paediatric patients in the emergency department (ED).

Methods The study design used was a retrospective longitudinal analysis based on medical chart review and a computer database. Except for a shorter list of complaints and some abnormal vital sign criteria modifications, the structure and triage process for applying Ped-TTAS was similar to that of the Paediatric Canadian Emergency Triage and Acuity Scale. Nontrauma paediatric patients presenting to the ED were triaged by well-trained triage nurses using the four-level Ped-TTS in 2008 and five-level Ped-TTAS in 2010. Hospitalisation rates and medical resource utilisation were analysed by acuity levels between the contrasting study groups.

Results There was a significant difference in patient prioritisation between the four-level Ped-TTS and five-level Ped-TTAS. Improved differentiation was observed with the five-level Ped-TTAS in predicting hospitalisation rates and medical costs.

Conclusions The five-level Ped-TTAS is better able to discriminate paediatric patients by triage acuity in the $\mathrm{ED}$ and is also more precise in predicting resource utilisation. The introduction of a more accurate acuity and triage system for use in paediatric emergency care should provide greater patient safety and more timely utilisation of appropriate ED resources.

\section{INTRODUCTION}

Paediatric emergency departments (EDs) frequently become congested with non-urgent patients, resulting in patients with high acuity conditions (such as altered consciousness, respiratory distress or haemodynamic compromise) experiencing delays in receiving appropriate management. The goal of paediatric ED triage is to prioritise patients rapidly and accurately based on acuity so that any critical medical needs can be met in a timely manner. Effective triage ensures that all ED patients are managed safely and assessed accurately according to their presenting condition.

In Taiwan the Department of Health and National Health Insurance (NHI) first mandated the use of the Taiwan Paediatric Triage System (Ped-TTS) in 1998. The Ped-TTS is a four-level triage system that classifies patients according to their vital signs and chief complaints/conditions.
There are 32 chief complaints and 18 vital sign values. The four-level Ped-TTS does not include trauma complaints or other common presentations such as ophthalmic, otorhinolaryngological or dental complaints, nor does it include a pain scale. No validity studies were undertaken to evaluate the efficacy of Ped-TTS.

With the growing demand for the use of paediatric EDs, an accurate paediatric triage scale is needed to support the provision of quality care being pursued by the specialty of Paediatric Emergency Medicine. Studies have also raised issues concerning the validity and reliability of paediatric triage in general. ${ }^{1-6}$ This may be related to inadequate triage training or insufficient standardisation of triage processes. ${ }^{7}$ Two review articles have suggested that the use of a valid and reliable five-level triage system can improve ED operations. $^{8} 9$ Furthermore, less structured triage systems are considered inadequate because they do not provide sufficient discrimination to stratify patients appropriately by acuity in high volume and overcrowded EDs. ${ }^{8}$

To address this, a new five-level Paediatric Triage and Acuity System (Ped-TTAS) was developed in parallel with the establishment of the five-level adult TTAS system by the TTAS National Working Group (NWG) in Taiwan. ${ }^{10} 11$ These were adapted from the adult and paediatric Canadian Triage and Acuity Scales. ${ }^{12} 13$ The new Ped-TTAS criteria and chief complaint list was developed by an 11-member emergency medicine expert panel (seven members from the Taiwan Society of Emergency Medicine and four from the Taiwan Association of Critical Care Nurses) that formed the TTAS NWG, using the Paediatric Canadian Emergency Triage and Acuity Scale (Paed-CTAS) and a literature review. Guidelines were adapted and modified by consensus whenever required to be pertinent to ED conditions in Taiwan. The content validity index for approved Ped-TTAS changes was between 0.8 and 1.0 .

The Ped-TTAS retains most of the features of the Paed-CTAS but includes some major modifications. The Ped-TTAS has shorter reassessment time intervals for acuity levels 1, 2, 3, 4 and $5(0,10,30$, 60 and $120 \mathrm{~min}$, respectively) and classifies chief complaints into two categories (non-trauma and trauma). The non-trauma category is similar to the Paed-CTAS and includes 12 categories with 74 chief complaints. The chief complaints in the trauma category are grouped by anatomical region and include15 categories with 47 chief complaints. 
Table 1 Comparison of the characteristics of the four-level Paediatric Taiwan Triage System and the five-level Paediatric Triage and Acuity System

\begin{tabular}{|c|c|c|}
\hline Criteria & Four-level Ped-TTS & Five-level Ped-TTAS \\
\hline $\begin{array}{l}\text { Time to triage } \\
\text { assessment }\end{array}$ & Not specified & $10 \mathrm{~min}$ \\
\hline $\begin{array}{l}\text { Time to physician } \\
\text { assessment }\end{array}$ & $\begin{array}{l}\text { Immediate } / 10 \mathrm{~min} / 30 \mathrm{~min} / \\
\text { none }\end{array}$ & Not specified \\
\hline $\begin{array}{l}\text { Time to nurse } \\
\text { reassessment }\end{array}$ & Not specified & Immediate/10/30/60/120 min \\
\hline $\begin{array}{l}\text { Triage decision } \\
\text { criteria }\end{array}$ & $\begin{array}{l}\text { Either vital signs or chief } \\
\text { complaints }\end{array}$ & $\begin{array}{l}\text { Complaints-based with first/ } \\
\text { second-order modifiers used }\end{array}$ \\
\hline $\begin{array}{l}\text { Chief complaints } \\
\text { list }\end{array}$ & $\begin{array}{l}4 \text { categories ( } 32 \text { chief } \\
\text { complaints); ophthalmic, } \\
\text { ENT and dental complaints } \\
\text { not included }\end{array}$ & $\begin{array}{l}12 \text { categories (74 chief } \\
\text { complaints); ophthalmic, ENT } \\
\text { and dental complaints included }\end{array}$ \\
\hline Pain scale & Severe and non-severe & 10-point Likert scale \\
\hline Injury mechanism & None & Yes \\
\hline $\begin{array}{l}\text { Implementation } \\
\text { guidelines }\end{array}$ & Not specified & Specified \\
\hline $\begin{array}{l}\text { Education } \\
\text { implementation } \\
\text { material }\end{array}$ & None & $\begin{array}{l}\text { Computer decision support } \\
\text { system and structured } \\
\text { educational material }\end{array}$ \\
\hline
\end{tabular}

Patients meeting explicit threshold levels for haemodynamic instability (appendix A) are considered as acuity level 1 in the Ped-TTAS. Pain scale revisions include the deletion of chronic pain to accommodate cultural expectations in Taiwan. A comparison between the two Taiwan triage systems is shown in table 1. An electronic clinical decision Ped-TTAS support tool (ePed-TTAS) was introduced during implementation to assist triage nurses to accurately apply the paediatric triage in Taiwan. The evaluation of the two triage systems is important as crowding in the ED continues to impose a heavy burden on emergency care providers in Taiwan.

The purpose of this study was to examine the effectiveness of the five-level Ped-TTAS by comparing its reliability in patient prioritisation and resource utilisation with the previous fourlevel Ped-TTS in non-trauma paediatric ED patients.

\section{MATERIALS AND METHODS Data collection}

This is a retrospective study using an administrative database from the hospital information system in the largest university-affiliated medical centre in Taiwan. The Ped-TTS was applied to ED patients from 1998 until 2009 (the transition year). Ped-TTAS was formally implemented in January 2010. The 2009 data were not used due to contamination related to changeover preparation and triage nurse training prior to implementing the new triage system. To account for this, the comparison of the two triage systems was made between the 2008 and 2010 data. Only data from non-trauma paediatric patients (aged $<18$ years) were used because the four-level triage system did not include trauma complaints or discriminator criteria for trauma patient triage level assignment.

Patient demographics, chief complaints, clinical outcomes and medical resource utilisation were extracted from the ED for validity analyses. The clinical outcomes included: discharged from ED, admission to a general ward, admission to paediatric intensive care unit and death. Medical resource utilisation was defined as medical costs incurred in the ED including nurse and physician fees, cost of medications and diagnostics, and medical materials.
We used a computerised version of the Ped-TTAS (ePed-TTAS), which was designed to assist triage nurses in decision-making at the point of care. The ePed-TTAS application was developed in strict compliance with the Ped-TTAS standards and provided the nurse with rapid access to the standardised complaints list. Content validity of the Ped-TTAS and ePed-TTAS was assessed and was shown to be comparable. After entry of the vital signs, the system automatically prompted the nurse to assign the appropriate triage level if the vital signs were abnormal or provided any other complaintspecific modifiers for patients with normal vital signs.

\section{Statistical analysis}

Data are summarised using descriptive statistics where numerical variables are presented as medians and IOR and categorical variables are expressed as frequency and percentage. The triage level of the two systems was treated as the independent variable. Hospitalisation rates and ED medical costs were analysed according to acuity levels. Multiple regression models adjusting for age, gender and chief complaint were used to compare differences and trends regarding hospitalisation (multiple logistic regression) and $\mathrm{ED}$ medical costs (multiple linear regression) among levels of triage and acuity. Log transformation was performed on ED medical costs before multiple linear regression analysis. All data were analysed using SAS V.9.12 (SAS, Cary, North Carolina, USA). A p value of $<0.05$ was considered statistically significant.

\section{RESULTS \\ Demographics}

A total of 85536 non-trauma paediatric emergency visits were identified during the study period; 662 cases (0.77\%) were excluded due to incomplete information (351 from 2008 and 311 from 2010), leaving a total of 84874 patient records for inclusion in the analysis. Of these, 42346 patients treated in 2008 were triaged using the four-level Ped-TTS and 42528 patients presenting in 2010 were triaged using the five-level Ped-TTAS.

The comparative characteristics of the two study groups are shown in table 2. There were no age or gender differences between the 2008 and 2010 paediatric presentations to the ED. Presentation volumes were the same by shift across both study periods and the overall admission rates were almost identical (22.91\% in 2008 and $22.06 \%$ in 2010) and the median ED length of stay was $84 \mathrm{~min}$ (IOR 38-192) and $85 \mathrm{~min}$ (IOR 38-178), respectively. The median $\mathrm{ED}$ cost was found to have increased from 1552 NT dollars (IOR 1171-2945) to 1627 NT dollars (IOR 1210-3031) over the two study periods $(p<0.001)$. The distribution of the top 15 chief complaints was highly consistent across the study periods (table 2 ).

\section{Comparative effectiveness of the two triage systems \\ Distribution of acuity}

The distribution by acuity level for each triage system is shown in table 2. There were $28.14 \%$ and $20.91 \%$ triaged as levels 1 and 2 , respectively, using the four-level Ped-TTS compared with $13.94 \%$ and $9.40 \%$ using the five-level Ped-TTAS, with nearly half of the patients (49.71\%) assigned acuity level 3 .

\section{Admission rate}

Using the four-level Ped-TTS, admission rates were $26.09 \%$ for level 1, 28.77\% for level 2, 20.09\% for level 3 and $14.63 \%$ for level 4. Using the five-level Ped-TTAS, admission rates were $27.83 \%, 36.39 \%, 21.86 \%, 15.56 \%$ and $8.94 \%$, respectively, for 
Table 2 Comparisons of patient demographics, triage acuity and ED process data between the two study groups

\begin{tabular}{|c|c|c|}
\hline & $\begin{array}{l}\text { Group 1* } \\
(\mathrm{N}=42346)\end{array}$ & $\begin{array}{l}\text { Group 2t } \\
(N=42528)\end{array}$ \\
\hline Age in years, median $\left(Q_{1}, Q_{3}\right)$ & $3(1,6)$ & $3(2,6)$ \\
\hline Male patients, n (\%) & $24085(56.88)$ & $24232(56.98)$ \\
\hline \multicolumn{3}{|l|}{ Acuity distribution, n (\%) } \\
\hline Level 1 & 11915 (28.14) & $5929(13.94)$ \\
\hline Level 2 & $8856(20.91)$ & $3996(9.40)$ \\
\hline Level 3 & $16229(38.32)$ & $21141(49.71)$ \\
\hline Level 4 & $5346(12.62)$ & $9516(22.38)$ \\
\hline Level 5 & & $1946(4.58)$ \\
\hline \multicolumn{3}{|l|}{ Shift distribution, n (\%) } \\
\hline $08: 00-16: 00$ & $14128(33.36)$ & 13901 (32.69) \\
\hline $16: 00-24: 00$ & $17471(41.26)$ & $17547(41.26)$ \\
\hline $00: 00-08: 00$ & $10747(25.38)$ & $11080(26.05)$ \\
\hline \multicolumn{3}{|l|}{ Final disposition, $\mathrm{n}(\%)$} \\
\hline Discharged from ED & 32639 (77.08) & 33146 (77.94) \\
\hline Admitted to ward & $9170(21.65)$ & $8789(20.67)$ \\
\hline Admitted to PICU & $530(1.25)$ & $591(1.39)$ \\
\hline Expired & $7(0.02)$ & $2(0.00)$ \\
\hline \multicolumn{3}{|l|}{ Medical resource utilisation } \\
\hline LOS in the ED (min), median $\left(0_{1}, Q_{3}\right)$ & $84(38,192)$ & $85(38,178)$ \\
\hline ED costs (NT dollars), median $\left(\mathrm{O}_{1}, \mathrm{O}_{3}\right)$ & $1552(1171,2945)$ & $1627(1210,3031)$ \\
\hline \multicolumn{3}{|l|}{ Chief complains, $\neq n(\%)$} \\
\hline Fever & $19271(45.51)$ & $19187(45.12)$ \\
\hline Vomiting and/or nausea & 3778 (8.92) & $4038(9.49)$ \\
\hline Cough & 3377 (7.97) & $3702(8.70)$ \\
\hline Abdominal pain & $3400(8.03)$ & $3387(7.96)$ \\
\hline Diarrhoea & $1885(4.45)$ & $1660(3.90)$ \\
\hline Rash & $1187(2.80)$ & $1281(3.01)$ \\
\hline Shortness of breath & $990(2.34)$ & $1037(2.44)$ \\
\hline URTI complaints & $459(1.08)$ & $759(1.78)$ \\
\hline Sore throat & $679(1.60)$ & $731(1.72)$ \\
\hline Localised swelling/redness & $545(1.29)$ & $522(1.23)$ \\
\hline Earache & $582(1.37)$ & $480(1.13)$ \\
\hline Seizure & $50(1.30)$ & $476(1.12)$ \\
\hline Headache & $410(0.97)$ & $421(0.99)$ \\
\hline Inconsolable crying in infants & $363(0.86)$ & $363(0.85)$ \\
\hline Foreign body & $171(0.40)$ & $279(0.66)$ \\
\hline Others & $4699(11.10)$ & $4205(9.89)$ \\
\hline
\end{tabular}

*Patients treated in 2008

tPatients treated in 2010.

†The top 15 chief complaints were identified and arranged in descending order of frequency from the 2010 patient presentations and the frequency was then compared with the 2008 presentations.

ED, emergency department; LOS, length of stay; PICU, paediatric intensive care unit; URTI, upper respiratory tract infection.

triage levels 1, 2, 3, 4 and 5. The ORs with 95\% CIs are shown in table 3 . The linear trend between decreasing acuity (from levels 1 to 4 or levels 1 to 5) and admission rate was calculated as 0.85 (95\% CI 0.83 to 0.87 ) and 0.78 (95\% CI 0.77 to 0.80$)$ for the four-level Ped-TTS and five-level Ped-TTAS, respectively. A statistically significant difference was observed, showing a higher strength of association between a lower admission rate and lower acuity using the five-level Ped-TTAS after adjusting for age, gender and chief complaint using multiple logistic regression models (table 3 ).

\section{Medical expenses}

A similar linear trend for decreasing medical costs with decreasing triage acuity was seen for both systems. The linear trend was calculated as -0.15 (95\% CI -0.15 to -0.14$)$ for the four-level Ped-TTS and -0.17 (95\% CI -0.18 to -0.17 ) for the five-level Ped-TTAS. A statistically significant difference was observed based on the decreasing ED medical costs using both triage systems, but a higher strength of association was found with the five-level Ped-TTAS after adjusting for age, gender and chief complaint using multiple linear regression models (table 3 ).

\section{DISCUSSION}

The CTAS was developed in the late 1990s by the Canadian Association of Emergency Physicians and National Emergency Nurses' Affiliation. ${ }^{14}$ In 2001 the Paediatric CTAS was first published $^{15}$ and then revised in 2008, ${ }^{12}$ designed to support programming into a Clinical Information System, allowing triage to become more simplified and standardised for better reliability. Studies have shown Paed-CTAS to have moderate to good reliability and validity. ${ }^{9} 16-20$

The Ped-TTAS was developed from the Paed-CTAS, and our study has shown that the five-level Ped-TTAS exhibits better discrimination than the four-level Ped-TTS. The triage criteria (modifiers) in the five-level Ped-TTAS are more consistent in physiological and risk identifying clinical descriptors than those found in the four-level Ped-TTS, which may explain why nearly half the children were classified as having lifethreatening or emergency conditions (levels 1 and 2) with the Ped-TTS compared with only $23.3 \%$ using the five-level Ped-TTAS. The five-level Ped-TTAS was better able to discriminate between high, intermediate and low acuity patients and to identify patients who were more seriously ill and needing prompt treatment, thus improving patient safety. Being able to assign an accurate triage acuity score reliably enables the prediction of patient volumes stratified by presentation type and severity. The five-level Ped-TTAS better supports the optimal use of patient placement and nurse and physician utilisation to deliver the most appropriate care to each patient group within the constraints of available resources.

The validation of a triage system requires that it is consistent with medical needs and also leads to a predictable outcome including morbidity, mortality, resource utilisation and cost. ${ }^{4} 10172122$ Our study demonstrated that triaging patients with the five-level Ped-TTAS led to greater discrimination in terms of measured outcomes such as total ED expenses and admission rates than the four-level Ped-TTS. Using multiple regression analysis, the five-level Ped-TTAS performed better than the previous four-level Ped-TTS (table 3). Similar differentiation between the two triage systems for adult patients in the ED was well demonstrated in our previous study. ${ }^{11}$

The admission rate in this study was $22.1-22.9 \%$, which is higher than previously reported paediatric $\mathrm{ED}$ admission rates of $3.0-17.0 \% .^{23-26}$ The higher admission rate in our study might be due to the implementation of NHI which covers the hospital cost. ${ }^{27} 28$

In previous studies examining the correlation between CTAS acuity and admission rate, $\mathrm{Ma}$ et al reported hospitalisation rates of $45 \%, 15 \%, 2.5 \%$ and $0 \%$ for CTAS levels $1-2,3,4$ and 5 , respectively, ${ }^{29}$ while two other studies reported rates of $63-100 \%$, $24-37 \%, 12-14 \%, 2-4 \%$ and $0-2 \%$ for levels $1-5$, respectively. ${ }^{19} 21$

Comparing our study results with those of others, ${ }^{19}$ we note that the percentage of patients in Ped-TTAS level 1 was more closely associated with a relatively low admission rate, suggesting that our patients were over-triaged. Upon further analysis, we determined that the absolute vital sign values set for the Ped-TTAS level 1 modifiers were over-sensitive. Other studies have also reported that over-reliance on vital sign values 
Table 3 Comparison of effectiveness between the two triage systems

\begin{tabular}{|c|c|c|c|c|c|c|c|c|}
\hline & \multicolumn{4}{|c|}{ Hospitalisation } & \multicolumn{4}{|c|}{ ER expenses (NT dollars) } \\
\hline & \multicolumn{2}{|l|}{ Ped-TTS } & \multicolumn{2}{|c|}{ Ped-TTAS } & \multicolumn{2}{|l|}{ Ped-TTS } & \multicolumn{2}{|l|}{ Ped-TTAS } \\
\hline & $\%$ & $\mathrm{OR}^{*}(95 \% \mathrm{Cl})$ & $\%$ & $\mathrm{OR}^{*}(95 \% \mathrm{Cl})$ & Median $\left(\mathbf{0}_{1}, \mathbf{O}_{3}\right)$ & $\beta \dagger(95 \%$ Cl) & Median $\left(\mathbf{0}_{1}, \mathbf{O}_{3}\right)$ & $\beta \dagger(95 \%$ Cl) \\
\hline 1 & $26.09 \%$ & 1.00 & $27.83 \%$ & 1.00 & $1869(1515,3393)$ & - & $2295(1894,3819)$ & - \\
\hline 2 & $28.77 \%$ & $1.13(1.06$ to 1.20$)$ & $36.39 \%$ & 1.37 (1.25 to 1.50$)$ & $1613(1248,3227)$ & $-0.12(-0.13$ to -0.10$)$ & $2573(1601.5,3801)$ & $-0.04(-0.06$ to -0.02$)$ \\
\hline 3 & $20.09 \%$ & $0.77(0.72$ to 0.82$)$ & $21.86 \%$ & 0.77 (0.72 to 0.82$)$ & $1348(1067,2530)$ & $-0.29(-0.30$ to -0.27$)$ & $1510(1227,2936)$ & $-0.34(-0.35$ to -0.32$)$ \\
\hline 5 & - & - & $8.94 \%$ & 0.33 (0.27 to 0.39 ) & - & - & $1055(910,1376)$ & $-0.72(-0.75$ to -0.70$)$ \\
\hline Trend & & 0.85 (0.83 to 0.87$)$ & & 0.78 (0.77 to 0.80$)$ & & $-0.15(-0.15$ to -0.14$)$ & & $-0.17(-0.18$ to -0.17$)$ \\
\hline
\end{tabular}

*Dependent variable: hospitalization (Y/N); performed with multiple logistic regression analysis adjusted by age, sex and chief complaints.

tDependent variable: In(ED expenses); performed with multiple linear regression analysis adjusted by age, sex and chief complaints.

ED, emergency department; Ped-TTS, Paediatric Taiwan Triage System; Ped-TTAS, Paediatric Triage and Acuity System.

identifies many patients who do not have serious conditions. ${ }^{30} 31$ During the development of Ped-TTAS, the TTAS NWG decided to remove all the vital sign values used in the previous four-level system except for the level 1 vital sign values, not wanting to miss potential life-threatening conditions in patients who did not appear to be acutely ill. This is at variance with the Paed-CTAS which provides nurses with tables of age-based vital signs and then uses the number of SDs from normal to support CTAS acuity selection. ${ }^{12}$ The TTAS NWG mandated vital signs to be recorded on all paediatric patients during their emergency visit. For patients identified as acuity levels 1 or 2 based on the critical first appearance, vital signs are measured during treatment. For patients assessed as levels $3-5$, vital signs are required as part of the triage process to confirm their Ped-TTAS score in order to determine whether it is safe for them to wait for treatment. Vital sign criteria were established according to the following age groups: $0-3$ months, $>3$ months to 3 years and $>3$ years. A review of our study groups showed that $84 \%$ of the Ped-TTAS level 1 patients were aged 3 months to 6 years. Given the stressful and chaotic environment of the $\mathrm{ED}$, we postulate that a number of patients initially identified as acuity levels $3-5$ had abnormal vital signs due to environmental or personal stress and were therefore assigned a level 1 score, resulting in an over-triaged group of patients. The present study used administrative data from the hospital information system. We did not review each patient's individual vital sign data and subject them to analysis, but we propose to do this as part of a future study.

There is no 'reference standard' measure of triage scale validity so, like other authors, we relied on a series of surrogate markers. ${ }^{22} 32$ The relationship between patient acuity level and outcome depends on surrogate outcome markers and the impact of confounding factors such as patient type and complexity, patient volumes, rate and surges of patient presentation and efficiency of care provided. ${ }^{32}$ However, if triage acuity is consistently applied, site-based year on year comparisons are very helpful to look for changes of case mix changes, patient safety, system and efficiencies, resource utilisation and patient outcomes derived from acuity changes.

While Ped-TTS had been used since 2008, there has been no standardised educational programme for nurses or an electronic decision support tool. The implementation of the new triage system Ped-TTAS, supported by an electronic decision support tool, was successfully used in a series of educational training initiatives. Prior to the formal implementation of the new Ped-TTAS system, all triage nurses were required to attend a $2 \mathrm{~h}$ education programme including 20 written triage scenarios as part of the training. Furthermore, the hospital information systems, ED charts and ED patient tracking systems were updated to reflect the new triage scale. The complaint-orientated triage structure adapted from CTAS facilitated the development of a highly functional electronic clinical decision support system assisting both education and triage at the point of care. Previous research has shown that an electronic triage tool is easy to learn, even by users unfamiliar with computers, and is readily accepted by triage nurses. ${ }^{33}$

\section{Limitations}

This study has a number of limitations. (1) It is a single-site retrospective study which may limit the generalisability. (2) Although the intervention is unlikely to have an effect as this is a retrospective study using an administrative database, the fact that the comparisons involved a healthcare environment that may have experienced other changes during the 2-year period should be taken into consideration. (3) The study cohorts did not include trauma cases because trauma triage criteria were not well-defined in the previous four-level Ped-TTS, so the results of this study are only applicable to non-trauma paediatric ED patients.

\section{Conclusions}

The five-level Ped-TTAS has significantly better predictability than the previous four-level Ped-TTS with regard to utilisation of medical resources. It is anticipated that an efficient emergency care system is required when medical resources are scarce under prospective payment systems such as the global budget system in Taiwan. However, triage tools are expected to have high sensitivity in discriminating emergency conditions in terms of risk management in paediatric care. It is important for triage systems to balance both patient safety and system efficiency. The cautious use of vital signs in different paediatric age groups is a critical issue for future designs of paediatric triage systems. Revisions of paediatric triage systems should include specific chief complaints while considering factors leading to over-triage as well as appropriate use of vital signs or age factors.

Acknowledgements The authors thank the CTAS National Working Group for granting the TTAS NWG permission to modify Paed-CTAS to meet our national needs, allowing them to create the Ped-TTAS. The authors also thank Professor M J Bullard for his advice and help in editing the manuscript. Special thanks for the statistical support from the Healthy Aging Research Centre at Chang Gung University, Taiwan. 
Contributors Y-CC: study concept and design, analysis and interpretation of data, drafting the manuscript, acquisition of data. C-JN: study concept and design, analysis and interpretation of data, drafting the manuscript, acquisition of data, study supervision. C-TW: acquisition of data, administrative, technical or material support. L-CC: acquisition of data, drafting the manuscript. J-CC: administrative, technical or material support. K-HH: study concept and design, data analysis and interpretation, drafting and revision of the manuscript, final proof reading, study supervision.

Funding The study was funded by grants from the Taiwan Department of Health (DOH100-TD-M-113-100004) and National Science Council (NSC-101-2410-H-182-015).

Ethics approval The study protocol was approved by the institutional review board. Competing interests None.

Provenance and peer review Not commissioned; externally peer reviewed.

Open Access This is an Open Access article distributed in accordance with the Creative Commons Attribution Non Commercial (CC BY-NC 3.0) license, which permits others to distribute, remix, adapt, build upon this work non-commercially, and license their derivative works on different terms, provided the original work is properly cited and the use is non-commercial. See: http://creativecommons.org/licenses/by-nc/3.0/

\section{REFERENCES}

1. Nakagawa J, Ouk S, Schwartz B, et al. Interobserver agreement in emergency department triage. Ann Emerg Med 2003;41:191-5.

2. Bergeron S, Gouin S, Bailey B, et al. Comparison of triage assessments among pediatric registered nurses and pediatric emergency physicians. Acad Emerg Med 2002;9:1397-401.

3. Travers DA, Waller AE, Katznelson J, et al. Reliability and validity of the emergency severity index for pediatric triage. Acad Emerg Med 2009;16:843-9.

4. vanVeen M, Steyerberg EW, Ruige M, et al. Manchester Triage System in paediatric emergency care: prospective observational study. BMJ 2008;337:a1501.

5. Maldonado T, Avner JR. Triage of the pediatric patient in the emergency department: are we all in agreement? Pediatrics 2004;114:356-60.

6. Bergeron S, Gouin S, Bailey B, et al. Agreement among pediatric health care professionals with the pediatric Canadian Triage and Acuity Scale guidelines. Pediatr Emerg Care 2004:20:514-18.

7. Chen SS, Chen JC, $\mathrm{Ng} \mathrm{CJ}$, et al. Factors that influence the accuracy of triage nurses' judgement in emergency departments. Emerg Med J 2010;27:451-5.

8. Fernandes $\mathbf{C M}$, Tanabe P, Gilboy N, et al. Five-level triage: a report from the ACEP/ENA Five-level Triage Task Force. J Emerg Nurs 2005;31:39-50.

9. van Veen M, Moll HA. Reliability and validity of triage systems in paediatric emergency care. Scand J Trauma Resusc Emerg Med 2009;17:38.

10. $\mathbf{N g} \mathbf{C J}$, Yen ZS, Tsai JC, et al. Validation of the Taiwan Triage and Acuity Scale: a new computerised five-level triage system. Emerg Med J 2010;28:1026-31.

11. $\mathbf{~ N g ~ C J , ~ H s u ~ K H , ~ K u a n ~ J T , ~ e t ~ a l . ~ C o m p a r i s o n ~ b e t w e e n ~ C a n a d i a n ~ T r i a g e ~ a n d ~ A c u i t y ~}$ Scale and Taiwan Triage System in emergency departments. J Formos Med Assoc 2010;109:828-37.

12. Warren DW, Jarvis A, LeBlanc L, et al. Revisions to the Canadian Triage and Acuity Scale Paediatric guidelines (PaedCTAS). CJEM 2008;10:224-32.
13. Bullard MJ, Unger B, Spence J, et al. Revisions to the Canadian Emergency Department Triage and Acuity Scale (CTAS) adult guidelines. CJEM 2008;10:136-42.

14. Beveridge R, Clarke B, Janes L, et al. Canadian Emergency Department Triage and Acuity Scale: implementation guidelines. CJEM 1999:1(Suppl):S2-8.

15. Warren D, Jarvis A, Leblanc L, et al. Canadian Paediatric Triage and Acuity Scale: implementation guidelines for emergency departments. CJEM 2001;3(Suppl):S1-27.

16. Gravel J, Gouin S, Manzano S, et al. Inter-rater agreement between nurses for the Pediatric Canadian Triage and Acuity Scale in a tertiary care center. Acad Emerg Med 2008:15:1262-7.

17. Gravel J, Gouin S, Bailey B, et al. Reliability of a computerized version of the Pediatric Canadian Triage and Acuity Scale. Acad Emerg Med 2007:14:864-9.

18. Gravel J, Gouin S, Goldman RD, et al. The Canadian Triage and Acuity Scale for children: a prospective multicenter evaluation. Ann Emerg Med 2012;60:71-7.

19. Gravel J, Manzano S, Arsenault M. Validity of the Canadian Paediatric Triage and Acuity Scale in a tertiary care hospital. CJEM 2009;11:23-8.

20. Ma W, Gafni A, Goldman RD. Correlation of the Canadian Pediatric Emergency Triage and Acuity Scale to ED resource utilization. Am J Emerg Med 2008;26:893-7.

21. Gouin S, Gravel J, Amre DK, et al. Evaluation of the Paediatric Canadian Triage and Acuity Scale in a pediatric ED. Am J Emerg Med 2005;23:243-7.

22. Dong SL, Bullard MJ, Meurer DP, et al. Predictive validity of a computerized emergency triage tool. Acad Emerg Med 2007;14:16-21.

23. Mintegui Raso S, Benito Fernandez J, Vazquez Ronco MA, et al. Children's unscheduled return visits to an emergency department. An Esp Pediatr 2000;52:542-7

24. Losek JD. Characteristics, workload, and job satisfaction of attending physicians from pediatric emergency medicine fellowship programs. Pediatric Emergency Medicine Collaborative Research Committee. Pediatr Emerg Care 1994; 10:256-9.

25. Chang YC, $\mathrm{Ng} \mathrm{CJ}$, Chen YC, et al. Practice variation in the management for nontraumatic pediatric patients in the ED. Am J Emerg Med 2010;28:275-83.

26. Chang YC, Lo HC, Tzeng YM, et al. Comparative clinical practice of residents and attending physicians who care for pediatric patients in the emergency department. Pediatr Emerg Care 2008;24:364-9.

27. Lee YC, Huang YT, Tsai YW, et al. The impact of universal National Health Insurance on population health: the experience of Taiwan. BMC Health Serv Res 2010;10:225.

28. Chang L. The effect of health payment reforms on cost containment in Taiwan hospitals: the agency theory perspective. J Health Care Finance 2011;38:11-31.

29. Ma W, Jarvis DA, Goldman RD. Paediatric Canadian Triage and Acuity Scale as a predictor for outcome and resource utilization. CJEM 2007:9:210-11.

30. Eitel DR, Travers DA, Rosenau AM, et al. The emergency severity index triage algorithm version 2 is reliable and valid. Acad Emerg Med 2003:10:1070-80

31. Cooper RJ, Schriger DL, Flaherty HL, et al. Effect of vital signs on triage decisions. Ann Emerg Med 2002;39:223-32.

32. Twomey $\mathbf{M}$, Wallis LA, Myers JE. Limitations in validating emergency department triage scales. Emerg Med J 2007;24:477-9.

33. Bullard MJ, Meurer D, Pratt $\mathrm{S}$, et al. Evaluation of triage nurse satisfaction with training and use of an electronic triage tool. Can J Emerg 2003:5:183-4. 